\title{
Research on the Factors of the Process of the Tacit Knowledge in Knowledge Service Enterprises
}

\author{
Chi Chen", Zhongyi Zhang", Li Chen" and Yongbo Lv*
}

Institute of Systems Engineering and Control, School of Traffic and Transportation, Beijing Jiaotong University, Beijing, 100044 China

\begin{abstract}
Current knowledge services enterprises have developed rapidly, and the core competitiveness lies in the tacit knowledge which is crux of the enterprises and the brain of employees, but is difficult to observe and disseminate. This paper is an account of the research conducted on the tacit knowledge process in knowledge services enterprises, considering the characteristics of the tacit knowledge, the subject of the knowledge, the object of the knowledge and the external environment to fully account for the factors influencing the tacit knowledge and its development, building a conceptual model and theoretical analysis regarding tacit knowledge in knowledge service enterprise. On the basis of the previous article and the empirical research data obtained through questionnaires and calculated using SPSS software for statistical analysis, correlation assumptions were made before testing and were discussed for the empirical results.
\end{abstract}

Keywords: Core competitiveness, knowledge service enterprises, SPSS software, tacit knowledge.

\section{THE RAISING OF QUESTIONS}

According to the difficulty in obtaining knowledge, the structural properties can be defined as explicit knowledge and tacit knowledge. Compared to explicit knowledge, tacit knowledge is difficult to be imitated or shared, and it is not easy for a competitor or any other person to steal or copy it, therefore it constitutes the core competitiveness of enterprises and forms the true source of sustainable competitive advantage of enterprises; In addition, tacit knowledge also has other relevant characteristics of being hard coded and a strong monopoly for hindering learning, transfer and exchange between the employees [1]. Current social enterprise knowledge services (consulting) have greatly developed; the most valuable core competitiveness of such enterprises is the tacit knowledge which is crux of the enterprises and the brain of employees [2]. But it is hard to inherit, as it is difficult to express, transfer, or diffuse problems. Therefore, how to effectively promote enterprise communication and sharing of tacit knowledge is the key to knowledge management, and in order to increasingly maximize the knowledge performance of the knowledge services enterprises, it is necessary for the enterprise to study the process of tacit knowledge.

Currently, many scholars have carried out a lot of research on the methods and evaluation of tacit knowledge, but the factors of tacit knowledge in the knowledge services business remain unstudied. During the explicit process of tacit knowledge research, there are many other factors that affect

*Address correspondence to these authors at the Beijing Jiaotong University, Beijing, 100044 China; Tel: +86-152-1058-3505; E-mails: davidchenchi@163.com,john_zhangzy@x263.net, aaa19850721@163.com, and yblv@mail.bjtu.edu.cn its externalization process, therefore a reasonable model must be established for its comprehensive analysis.

\section{RESEARCH METHODOLOGIES}

\subsection{Knowledge Services Enterprises Tacit Knowledge Process}

\subsubsection{Knowledge Connotation Service Enterprises}

Knowledge Services (KSP) commonly refers to the consulting services for the main business of the company, which is also known as the consulting industry sectors [3]. As decision-making and operational consulting individuals and organizations provide intellectual services to the industry, they increasingly provide broader prospects for the development of consulting industry to achieve rapid expansion in modern society. Unlike industrial entities, the output of consulting industry is not the material goods, nor does it provide a simple alternative to conventional business services, instead it provides intelligence services to individuals, organizations, businesses and industries, and has its own characteristics. Its product is not a visible intellectual product, but a high degree of knowledge of the properties [4]. The advisory service itself also has a one-time, unique binding, and other risks and various other interactivity distinctive characteristics which distinguish it from other services.

\subsubsection{The Tacit Knowledge Forward to Explicit Knowledge}

a. Mechanism of Tacit Knowledge

In the course of the study on the structure of knowledge, particularly, the process of tacit knowledge is termed as explicit knowledge by gradually transforming it into the most classic models -SECI model. Famous Japanese scholars Konno (Konno) and Nonaka (Nonaka) have considered new knowledge generated in the conversion process of tacit and 
explicit knowledge, by converting the process of tacit knowledge and explicit knowledge into four different types, proposing a different classification of SECI knowledge transformation model [5]. First, the process of socialization (socialization) refers to the process of knowledge from tacit to tacit conversion; the second is an external process (externalization) which refers to the process of knowledge from tacit to explicit conversion; the third is the fusion process (combination) which refers to the explicit knowledge from explicit conversion process; the fourth is internal process (internalization) referring to the process of knowledge from explicit to implicit conversion. In the course of these four processes, externalization process (from tacit knowledge to explicit knowledge) for profiling and transfer of tacit knowledge diffusion provides a way which is usually the enterprise needs for special and enhanced attention. The concept is a transformation process of externalizing tacit knowledge through presentation translating it into a clear and easy to understand form of explicit knowledge. But the most important part is how to find the right way to effectively express the tacit knowledge, not necessarily through writing but only through expressions and feelings.

Groups of Tacit Knowledge System: for employees, the business community has brought a sense of belonging, responsibility and identity, helping in carrying out the process of tacit knowledge. However, business groups not just comprise of the entire enterprise within the meaning of a great organization, but also or mainly refer to internal staff spontaneously forming small groups [6]. Such small groups are not mechanically divided by department or business, but by small groups of self-organized community-style staff to tacit knowledge among employees dominance, such as exons, exchange, transfer, diffusion, etc. providing sufficient activity incentives. These knowledge communities contain some of the main features, such as building more intimate and trusting environment and atmosphere. Trusts can promote the members of the group to willingly share the internal knowledge, and such willingness continues to inspire and sustain knowledge sharing behaviour. These knowledge sharing members form a spiral upward trend in favour of making tacit knowledge explicit. And when trust within the group is more in the form of insufficient competition, the externalization process of tacit knowledge may slow down or even come to a halt.

Market mechanisms Tacit Knowledge: because of the characteristics of tacit knowledge, it is difficult to observe market mechanisms tacit knowledge, and therefore it has a high degree of privacy and it is hard to manage. Tacit knowledge is often present in the minds of the employees themselves; naturally, it cannot avoid holders from having a "self-interest" idea that has its own unique technology and knowledge. Out of internal competition between companies or groups and the urge to protect their special status considerations, the owner of tacit knowledge does not easily share with others, which is normal market mechanism, and is reasonable. Therefore, companies should not and can not be forced to solicit and deprive the employees of the tacit knowledge, butonly to motivate employees to consciously devote to the enterprise through the tacit knowledge management, rewards, recognition, support and other means, and ultimately enhance the company's core competitiveness. Tacit knowledge is consistent with the use of market mecha- nisms and the interest of a social transformation mechanism requires knowledge of business development.

\section{b. Factors Making Tacit Knowledge Explicit}

Due to various causes originated from its nature and the external factors, it should be clearly realized that tacit knowledge is hard to be made explicit to some extent, thus the need to insistently endeavour to seek methods is required to make it explicit. The following are some of the factors that play a role in making tacit knowledge explicit.

The special features of tacit knowledge are major constraints that influence its explication level. The first is its hidden degree. Since it is difficult to describe the tacit knowledge explicitly, therefore the greater the hidden degree , the harder it is to be transferred. The second is its complexity. The ineffable tacit knowledge is explained in a large amount of coding knowledge and information. More difficulty is confronted in making the tacit knowledge explicit as its complexity increases. The last one is the level of its systematization. As tacit knowledge usually roots in a greater knowledge system, it is necessary to integrate such tacit knowledge and other related knowledge so as to reach systematized knowledge and make it organized. And then the systematized knowledge can be explained and described [7]. Generally, the more non-ordering the tacit knowledge system , the more difficult it is to make it e explicit.

The body of knowledge (the owner of knowledge): Most of the tacit knowledge is owned by individuals. Even the collective culture is always dependent on a single person. In other words, tacit knowledge has strong dependency on individuals [8]. Furthermore, the knowledge of owner's capability, knowledge spreading awareness and dissemination are important factors that restrict tacit knowledge transfer.

The object of knowledge (the knowledge receiver): as seen from object's influences, the tacit knowledge transfer is an increasing function of the receiver's willingness to absorb knowledge, the insight to search knowledge source, the sensitivity to foresee the market potential of intellectual products and the ability to receive tacit knowledge.

In addition, the abilities mentioned above are closely related to the knowledge of receiver's EQ and IQ such as mode of thinking, learning competence, savvy, ability of communication and decoding ability. In a word, comprehensive quality has a direct and remarkable impact on the process and pace of tacit knowledge transfer. To sum up, the rate of knowledge transfer has a positive relationship with the receiver's level of knowledge and comprehensive quality.

The correlation between the body and the object of knowledge: the connected factors of the body and the object of knowledge dominate the number, extent, channel and mode through which the tacit knowledge is transferred to explicit knowledge. The first is similarity. It refers to the likeness and relative approach degree between the owner and the receiver in terms of linguistic background, knowledge background, cultural background, cognitive pattern and cultural deposit. Tacit knowledge transfers much more easily and substantially as the owner and the receiver share more similar or closer backgrounds. The second is diversity. Such differences between the owner and the receiver as profes- 


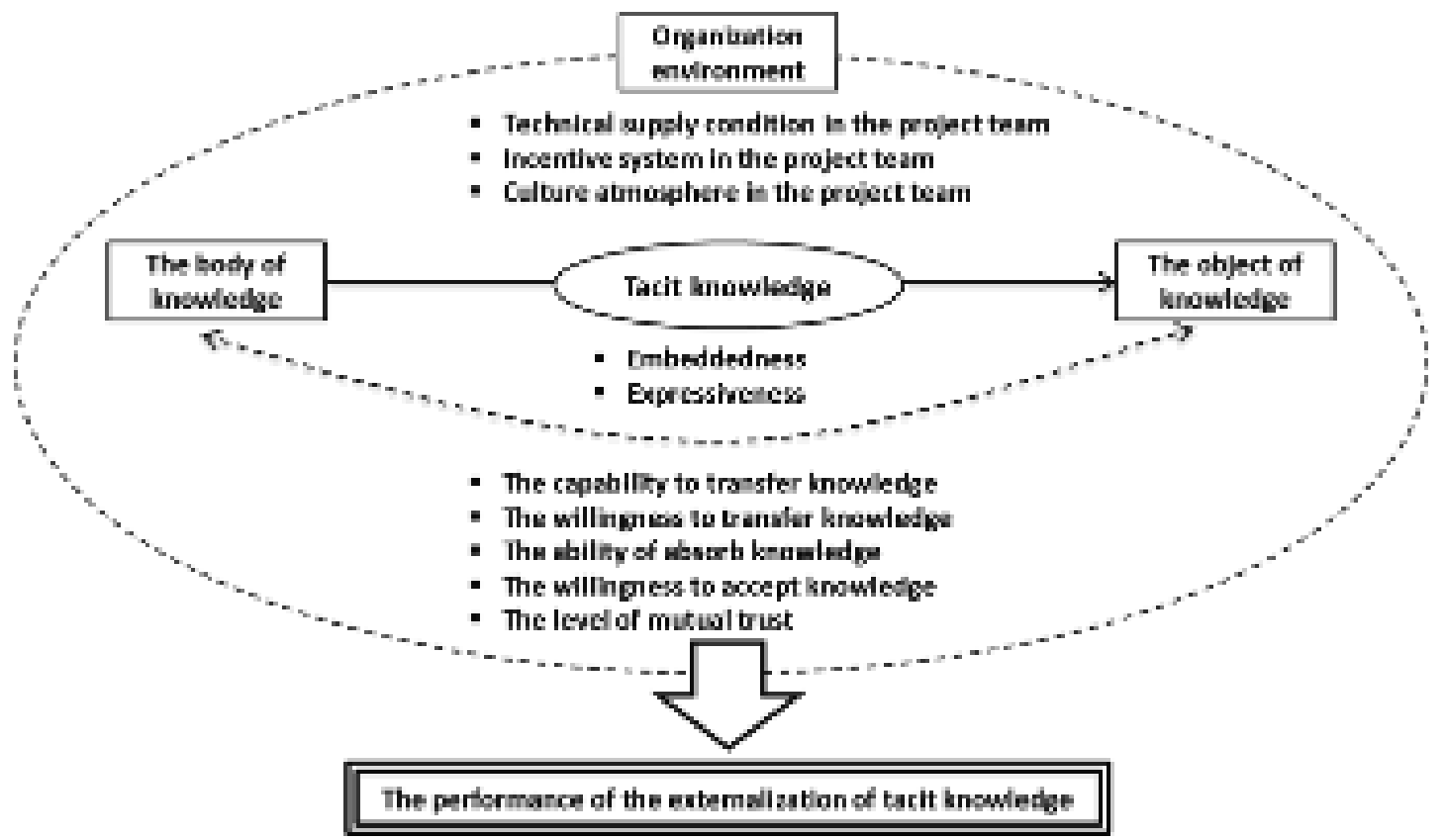

Fig. (1). the conceptual model of factors affecting the externalization of tacit knowledge in knowledge service project.

sion, culture, cognitive ability, mode of thinking and knowledge structure are restriction factors affecting the efficiency and order of knowledge transference and knowledge diffusion. The third is overlap. When the owner and the receiver, acting as the supply and the demand side, reach an agreement, the partially overlapped or communicated cognitive pattern and knowledge structure will, on the condition that the two are willing to transfer and exchange their knowledge, facilitate the externalization of tacit knowledge. The fourth is complementarity. If the knowledge structure and cognitive pattern are complementary, and the receiver is interested in such tacit knowledge at the same time, the progress of tacit knowledge transformation will be smooth.

The environment of the organization: In the environment of an organization, tacit knowledge transfer is measured by organizational culture, organization system, proposed system, technology system and social environment [9].

\subsection{The Conceptual Model Construction of the External- ization of Tacit Knowledge in Knowledge Service Project}

\subsubsection{Model Specification}

The thesis of combining theoretical research with empirical study constructs a conceptual model for the externalization of tacit knowledge in knowledge service project on the basis of the relationship between the independent and dependent variables, including all the factors that play a role in influencing the externalization of tacit knowledge as comprehensively as possible, see Fig. (1) below. At the bottom of the overall framework of the model, it is the performance of the externalization of tacit knowledge which is the dependent variable in this thesis and the goal in the course of the externalization of tacit knowledge. The performance will change as the three independent variables at the top of the framework change. The three independent variables are:

Factors related to the owner and receiver of knowledge transfer (the willingness to transfer knowledge, the capability of transfer knowledge, the willingness to accept knowledge, the ability to absorb knowledge, the level of mutual trust), factors related to the knowledge transferred (expressiveness and embeddedness) and factors related to the environment in which knowledge is transferred (incentive system, culture atmosphere, project team and technical supply condition).

The independent variables in Fig. (1) are selected after an analysis of the object, research scope and research purpose in this thesis, with reference to a lot of recent related articles. The research scope of this thesis is the externalization of tacit knowledge in knowledge-based service enterprises. Knowledge-based service enterprises are commonly called consulting services in the light of the analysis above. As these services are typical knowledge-intensive enterprises, knowledge plays an important role in their management. The conceptual model, built on the theoretical analysis of the factors affecting the externalization of tacit knowledge mentioned above, is constructed through the combination of elements that influence the performance of the externalization of tacit knowledge in knowledge service projects. Relevant theoretical hypotheses are also presented in this thesis.

\subsubsection{The Proposition of the Hypothesis}

This section proposes a hypothesis and analyzes the ten factors mentioned above in detail. Relationships between these factors and the dependent variables (the performance of the externalization of tacit knowledge) are further analyzed by an empirical study.

a. The relationship between the subject of transfer and the performance of the externalization of tacit knowledge.

The relationship between the subject of transfer and the performance of the externalization of tacit knowledge can be further divided into questions on how the performance of the externalization of tacit knowledge responses to the transfer party, the receiver and the relation of the transfer party and the receiver. 
b. The relationship between the knowledge transferred and the performance of the externalization of tacit knowledge.

The relationship between the tacit knowledge of knowledge management projects transferred and the performance of the externalization of tacit knowledge is researched from the expressiveness and embeddedness of the tacit knowledge.

c. The relationship between the environment in which knowledge is transferred and the performance of the externalization of tacit knowledge.

This thesis mainly studies the incentive system, technical supply condition and culture atmosphere in the project team to explore the relationship between the environment in which knowledge is transferred and the performance of the externalization of tacit knowledge. Fig. (1) presents the theoretical hypotheses in this thesis.

\section{RESULTS AND DISSCUSSION}

\subsection{Acquiring Data and the Analysis of it}

This part, based on the theoretical analysis above, checks the related hypothesis and then puts it forward by obtaining empirical study data and conducting statistical analysis through questionnaire using SPSS.

\subsubsection{Questionnaire Design and Investigation}

These questionnaires were issued to 16 enterprises in Shanghai and Tianjin through friends and classmates by e- mail or questionnaire in writing. 160 questionnaires were issued and 148 received in the investigation. The recovering rate reached $92.5 \%$. In the recovering questionnaires, 146 copies were available, with the rate of availability being $98.65 \%$. Through the descriptive statistical analysis of available ones, general characteristics were known of the respondents. As the investigation refers to people of different positions, ages and educational backgrounds and questionnaires were issued in Shanghai, Tianjin etc., the samples were general.

The index of questionnaires contained two parts: dependent variable and independent variable. Dependent variable is recessive knowledge and dominance performance. The independent variable includes knowledge transfer object, transfer knowledge and transfer circumstances with total indexes of 10.

\subsubsection{Factor Analysis}

To analyze related relationship among variables and check the above-mentioned hypothesis, this chapter used Enter in SPSS statistical software as regression analysis method, checking its related relationship and impact through multiple linear regression analysis of dominant performance of the regressive knowledge by factors. Before formal regression analysis, to avoid situation trouble caused by high dependency among independent variables, this paper, at first, made pairwise analysis of Pearson correlation coefficient. The correlation coefficient analysis results among independent variables are present in Table $\mathbf{1}$. The results demonstrate that high dependency did not exist in independent variables.

Table 1. The summary of theoretical hypotheses in this thesis.

\begin{tabular}{|c|c|c|}
\hline & Project & Relevant Hypotheses \\
\hline \multirow{5}{*}{$\begin{array}{l}\text { The subject } \\
\text { of transfer }\end{array}$} & \multirow{2}{*}{ The transfer party } & $\begin{array}{l}\text { H1: the performance of the externalization of tacit knowledge is significantly and positively correlated } \\
\text { with the consultant's knowledge transfer capacity }\end{array}$ \\
\hline & & $\begin{array}{l}\mathrm{H} 2 \text { : the performance of the externalization of tacit knowledge is significantly and positively correlated } \\
\text { with the consultant's willingness to transfer knowledge }\end{array}$ \\
\hline & \multirow{2}{*}{ The receiver } & $\begin{array}{l}\text { H3: the performance of the externalization of tacit knowledge is significantly and positively correlated } \\
\text { with the consultant's knowledge absorptive capacity }\end{array}$ \\
\hline & & $\begin{array}{l}\text { H4: the performance of the externalization of tacit knowledge is significantly and positively correlated } \\
\text { with the consultant's willingness to accept knowledge }\end{array}$ \\
\hline & $\begin{array}{l}\text { the relation of the transfer } \\
\text { party and the receiver }\end{array}$ & $\begin{array}{l}\text { H5: the performance of the externalization of tacit knowledge is significantly and positively correlated } \\
\text { with the level of mutual trust among consultants }\end{array}$ \\
\hline \multirow{2}{*}{\multicolumn{2}{|c|}{ Knowledge transferred }} & $\begin{array}{l}\text { H6: the performance of the externalization of tacit knowledge is significantly and negatively correlated } \\
\text { with the Embeddedness of tacit knowledge }\end{array}$ \\
\hline & & $\begin{array}{l}\text { H7: the performance of the externalization of tacit knowledge is significantly and positively correlated } \\
\text { with the expressiveness of tacit knowledge }\end{array}$ \\
\hline \multirow{3}{*}{\multicolumn{2}{|c|}{$\begin{array}{l}\text { The environment in which Knowledge is } \\
\text { transferred }\end{array}$}} & $\begin{array}{l}\text { H8: the performance of the externalization of tacit knowledge is significantly and positively correlated } \\
\text { with the incentive system in the project team }\end{array}$ \\
\hline & & $\begin{array}{l}\text { H9: the performance of the externalization of tacit knowledge is significantly and positively correlated } \\
\text { with the technical supply condition in the project team }\end{array}$ \\
\hline & & $\begin{array}{l}\text { H10: the performance of the externalization of tacit knowledge is significantly and positively correlated } \\
\text { with the learning culture in the project team }\end{array}$ \\
\hline
\end{tabular}


Table 2. Dependency analysis among independent variables.

\begin{tabular}{|c|c|c|c|c|c|c|c|c|c|c|}
\hline & $\begin{array}{l}\text { Embed- } \\
\text { dedness } \\
\text { Degree }\end{array}$ & $\begin{array}{c}\text { Expressive- } \\
\text { ness }\end{array}$ & $\begin{array}{c}\text { Transfer- } \\
\text { ring Ability }\end{array}$ & $\begin{array}{l}\text { Transfer- } \\
\text { ring Will }\end{array}$ & $\begin{array}{c}\text { Absorption } \\
\text { Ability }\end{array}$ & $\begin{array}{c}\text { Receiving } \\
\text { Will }\end{array}$ & $\begin{array}{c}\text { Mutual } \\
\text { Trust }\end{array}$ & $\begin{array}{l}\text { Technology } \\
\text { Conditions }\end{array}$ & $\begin{array}{l}\text { Encourag- } \\
\text { ing System }\end{array}$ & $\begin{array}{c}\text { Learning } \\
\text { Culture }\end{array}$ \\
\hline $\begin{array}{l}\text { embed- } \\
\text { dedness } \\
\text { degree }\end{array}$ & 1 & & & & & & & & & \\
\hline $\begin{array}{c}\text { expressive- } \\
\text { ness }\end{array}$ & 0.144 & 1 & & & & & & & & \\
\hline $\begin{array}{l}\text { transferring } \\
\text { ability }\end{array}$ & -0.039 & 0.02 & 1 & & & & & & & \\
\hline $\begin{array}{c}\text { transferring } \\
\text { will }\end{array}$ & -0.407 & -0.053 & 0.179 & 1 & & & & & & \\
\hline $\begin{array}{c}\text { absorption } \\
\text { ability }\end{array}$ & -0.059 & 0.192 & 0.163 & 0.075 & 1 & & & & & \\
\hline $\begin{array}{c}\text { receiving } \\
\text { will }\end{array}$ & -0.332 & -0.183 & 0.242 & 0.489 & 0.009 & 1 & & & & \\
\hline mutual trust & -0.276 & -0.015 & 0.183 & 0.417 & -0.179 & 0.256 & 1 & & & \\
\hline $\begin{array}{l}\text { technology } \\
\text { conditions }\end{array}$ & -0.263 & -0.228 & 0.041 & 0.389 & -0.076 & 0.241 & 0.352 & 1 & & \\
\hline $\begin{array}{c}\text { encouraging } \\
\text { system }\end{array}$ & -0.361 & -0.192 & 0.115 & 0.573 & 0.078 & 0.331 & 0.542 & 0.611 & 1 & \\
\hline $\begin{array}{l}\text { learning } \\
\text { culture }\end{array}$ & -0.223 & -0.076 & 0.065 & 0.553 & 0.005 & 0.279 & 0.407 & 0.417 & 0.58 & 1 \\
\hline
\end{tabular}

Table 3. Checking table of regression coefficient and dominance coefficient.

\begin{tabular}{|c|c|c|c|c|c|c|c|}
\hline \multirow[t]{2}{*}{ Model } & \multicolumn{2}{|c|}{ Non-Standard Coefficient } & \multirow{2}{*}{$\frac{\text { Standard Coefficient }}{\text { Beta }}$} & \multirow[t]{2}{*}{$\mathbf{t}$} & \multirow[t]{2}{*}{ Significance } & \multicolumn{2}{|c|}{ Collinearity Statistics } \\
\hline & B & Standard Error & & & & Allowance & VIF \\
\hline (constant) & -1.151 & 0.385 & & -2.989 & 0.004 & & \\
\hline L1 embeddedness degree & -0.019 & 0.48 & -0.021 & -0.411 & 0.681 & 0749 & 1.331 \\
\hline L2 expressiveness & 0.112 & 0.035 & 0.165 & 3.158 & 0.002 & 0.813 & 1.229 \\
\hline L7 transferring ability & 0.119 & 0.046 & 0.131 & 2.517 & 0.012 & 0.886 & 1.126 \\
\hline L3 transferring will & 0.349 & 0.059 & 0.359 & 5.843 & 0.000 & 0.586 & 1.658 \\
\hline L8 absorption ability & 0.179 & 0.052 & 0.171 & 2.627 & 0.01 & 0.733 & 1.356 \\
\hline L6 receiving will & 0.168 & 0.054 & 0.169 & 3.078 & 0.003 & 0.719 & 1.386 \\
\hline L5 mutual trust & 0.103 & 0.047 & 0.125 & 2.142 & 0.032 & 0.645 & 1.541 \\
\hline $\begin{array}{l}\text { L11 technology condi- } \\
\text { tions }\end{array}$ & 0.089 & 0.063 & 0.086 & 1.425 & 0.153 & 0.611 & 1.663 \\
\hline L9 encouraging system & 0.175 & 0.067 & 0.198 & 2.593 & 0.011 & 0.371 & 2.659 \\
\hline L10 learning culture & 0.148 & 0.051 & 0.12 & 2.038 & 0.45 & 0.572 & 1.739 \\
\hline
\end{tabular}

Related analysis can only be taken as reference checking if there exists collinearity among independent variables in regression analysis. To check whether there is multicollinearity in variables, the reference can be made to the three standards: tolerance, VIF and CI (Wu Minglong, 2003). This paper chooses the first and second standards and one with high dependency among variables ( $>0.7)$ as diagnosis basis of collinearity. The value of tolerance is between 0 and 1 . If 
Table 4. Summary of empirical research results.

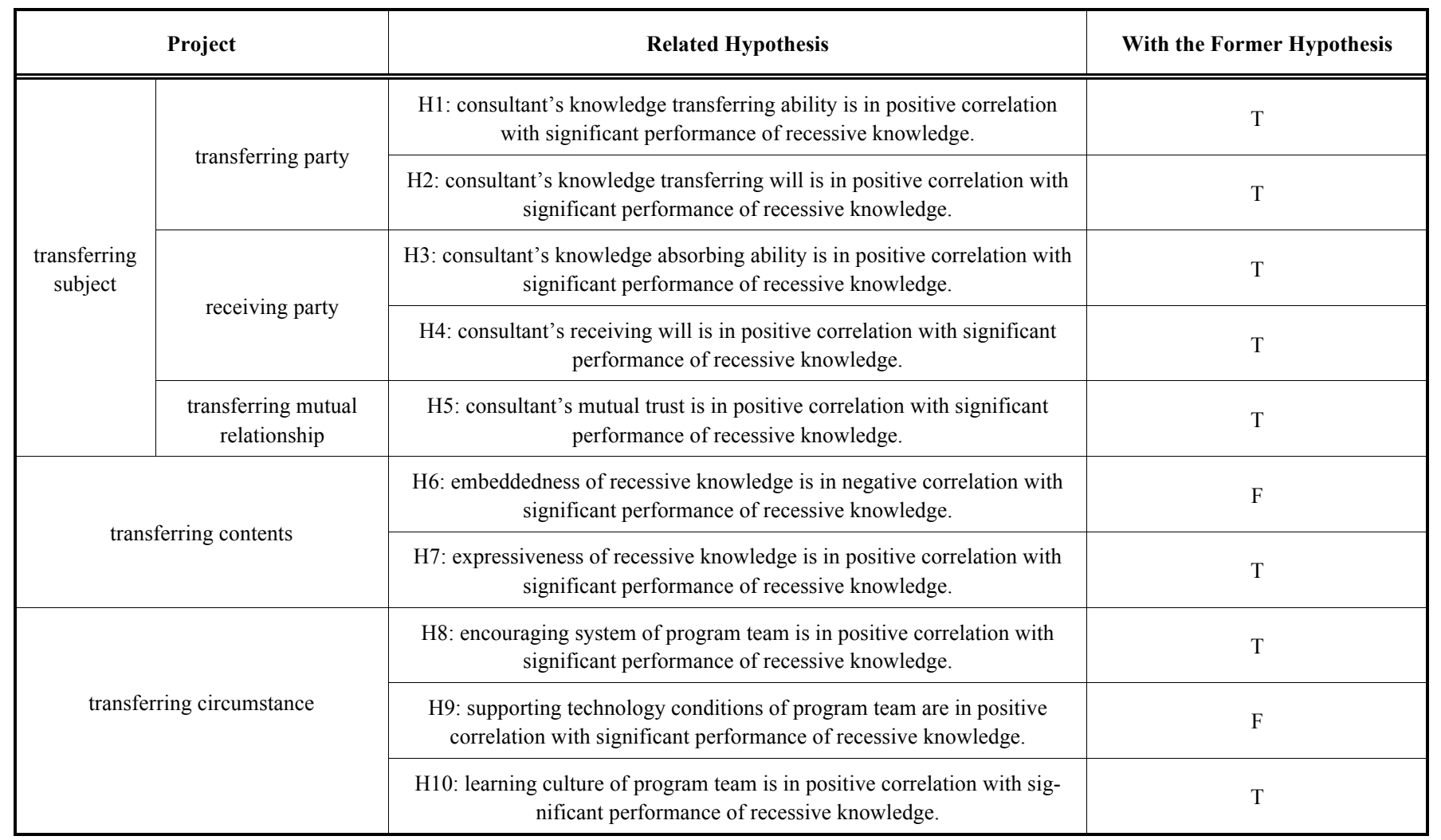

the tolerance of an independent variable is too low, then collinearity exists in this independent variable and the other. VIF is the reciprocal of tolerance. The higher the VIF, the lower is the tolerance of an independent value, and the more capable is the collinearity. Generally, if VIF is lower than 10 , multicollinearity does not exist in variables (Neter et al, 1985). Independent variable diagnosis results in regression analysis as shown in Table 2 . From the results, the lowest VIF of all the variables is 1.126 , with the highest being 2.659. And most of them are about 2 , being much more lower than marginal value 10 . Therefore, collinearity existing in variables can be rejected. In Table 3 , general effect of regression is shown. Dominance $\mathrm{P}=0.00, \mathrm{~F}$ value $=32.148$. It can be acknowledged that the whole equation of linear regression is marked. In the regression analysis, transfer party's recessive knowledge transferring will, ability, receiving party's receiving will, recessive knowledge absorbing ability and expressiveness, , encouraging system and dominant performance of recessive knowledge are equipped with conspicuous relationship. Besides, in regression analysis, embeddedness of recessive knowledge and t value of team's technology conditions is lower than 2 , with dominance being higher than 0.05 . In the science of statistics, the two independent variables influence the dependent variables to some extent. Relatively lower dominance and former hypothesis (H6, H9) are not null.

\section{CONCLUSION}

Based on the literature and live interview, this chapter made use of the questionnaires to carry out empirical analysis on factors of dominance process of recessive knowledge in service enterprises and to check hypothesis by putting it forward in Chapter 3. Starting from the basic factors related to transferring knowledge, the main factors were sought and also their influence on dominance process of recessive knowledge was checked. The result shows that transferring will, absorption ability, transferring ability, expressiveness and receiving have an important impact on dominance process of recessive knowledge. Encouraging system and learning culture influence expanding and transferring of recessive knowledge to some extent. Embeddness and technology have no significant influence on dominance of recessive knowledge. All in all, all the checking results regarding the hypotheses in this paper are shown in Table 4. Most of them are supported, but some hypotheses are not supported, such as hypotheses $\mathrm{H} 7$ and $\mathrm{H} 9$.

According to the above analysis, this paper holds that among the factors affecting recessive knowledge, many can be regulated and controlled by enterprises. Therefore, in practice, if dominance of recessive knowledge of knowledge serving enterprises is to be obtained, the following criteria should be met: (1) paying much attention to cultivating knowledge transferring and absorbing ability of the team members. Knowledge-serving enterprises may enroll professional counsel with experience and knowledge to contribute to sharing and expanding of recessive knowledge in enterprises, enhancing volume, depth and breadth of recessive knowledge in enterprises through strengthening the training; (2) enhancing transferring will of knowledge-serving subject to recessive knowledge continuously. Research results show that knowledge transferring party's transferring will is the biggest factor influencing dominance of recessive 
knowledge. Recessive knowledge transfer in enterprises and groups mainly lies in whether the member mastering recessive knowledge is willing to share it with others and transform the individual knowledge into group knowledge; and (3) creating learning culture atmosphere of recessive knowledge. Program team's cultural atmosphere reflects its attention to knowledge transferring. Besides, team learning cultural atmosphere should be established based on the relationship trust.

\section{CONFLICT OF INTEREST}

The authors confirm that this article content has no conflict of interest.

\section{ACKNOWLEDGEMENTS}

The author would like to thank his collaborators from and support of National Science \& Technology Infrastructure Center (2013DDJ1ZY06), Science and technology evaluation and statistics work methods of Ministry of Science and Technology (2013SE-0603).

\section{REFERENCES}

[1] M. Bhardwaj, and J. Monin, "Tacit to explicit: an interplay shaping organization knowledge," Journal of Knowledge Management, vol. 3, pp. 72-85, 2006.
[2] A. Smedlund, "Social network structures for explicit, tacit and potential knowledge," International Journal of Knowledge Management, vol. 1, pp. 78-87, 2009.

[3] I. Virtanen, "In Search for a Theoretically Firmer Epistemological Foundation for the Relationship Between Tacit and Explicit Knowledge," Electronic Journal of Knowledge Management, vol. 2, pp. 118-126, 2013.

[4] J. M. Bloodgood, and M. A. Chilton, "Performance implications of matching adaption and innovation cognitive style with explicit and tacit knowledge resources," Knowledge Management Research \& Practice, vol. 2, pp. 106-117, 2012.

[5] T. Okuda, "A new transforming method from tacit knowledge to explicit knowledge by using humanoid robot for verbalization," in 2007 IEEE International Professional Communication Conference, IPCC, Seattle, WA, USA, pp. 79-88, 2007.

[6] X. Wu, Z. Gao, and S. Wei, "An empirical research on tacit Knowledge explicitation and technologic innovation performance," Studies in Science of Science, vol. 25, pp. 1233-1238, 2007.

[7] M. He, and Y. Li, "The Research for Tacit Knowledge Explicating Based on Distributed Cognition," Journal of Intelligence, vol. 29, pp. $49-54,2010$.

[8] X. Li, C. Zhou, and H. Hu, "From craftsman's control to managerial control-A research on tacit knowledge explicitation in scientific management," Science and Technology Management Research, pp. 193-204, 2014.

[9] H. Cheng, and L. Wan, "A Study on Process and Mechanism of Making Enterprise Tacit Knowledge Explicit," Journal of Intelligence, vol. 29, pp. 118-121, 2010.

Received: June 10, 2015

Revised: July 29, 2015

Accepted: August 15, 2015

(C) Chen et al.; Licensee Bentham Open.

This is an open access article licensed under the terms of the (https://creativecommons.org/licenses/by/4.0/legalcode), which permits unrestricted, noncommercial use, distribution and reproduction in any medium, provided the work is properly cited. 